\title{
Straight Shank Ball End Cutter Machining Simulation System Shuai Li
}

\author{
Zaozhuang University, Zaozhuang 277160, China
}

Keywords: straight shank ball end mills; rake face; blade; Visual Basic; Solidworks

\begin{abstract}
Based on the Solidworks platform, using Visual Basic two development tool,according to the straight shank ball end cutter rake face grinding relationship,establish the simulation machining system, shorten the cycle of design, provide a basis for optimization of grinding parameters for later edge.
\end{abstract}

\section{Introduction}

In the process of complex curved surface, computer simulation technology has been widely applied. Straight shank ball end cutter rake face shape is more complex, its forming is achieved by strong grinding wheel, size, posture and wear process of grinding wheel will directly influence the use performance of ball end mills, in order to optimize the grinding parameters, the need to establish a rake face grindingmachining simulation system.

\section{Simulation system principle}

In order to display graphics for qualitative, quantitative analysis of interference, the system uses a direct solid modeling method ${ }^{[1]}$. The three-dimensional model are established and the straight shank grinding ball end cutter blank, according to theprocessing diagram (Fig.1) set the grinding parameters ${ }^{[2]}$, using CSG (ConstructiveSolid Geometry) method to record the blank and the wheel scan area, then the application of regional set difference from the Mao Pizhong order minus scanning ${ }^{[3]}$, and the front knife straight shank ball nose end milling cutter with the cutting process is constantly updated, so as to complete the whole process simulation.

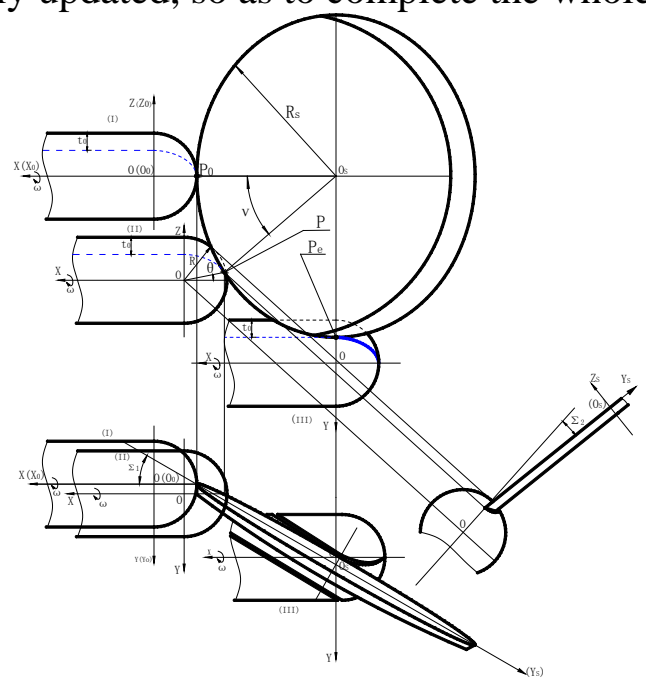

Fig. 1 The ball end cutter grinding process diagram

\section{Straight shank ball end cutter blank and wheel parametric modeling}

In order to optimize the grinding parameters or for error analysis, the establishment ofa number of different dimensions of the grinding wheel cutter blank and various types of experimental needs, in order to avoid duplication of labor, shorten the period of development, must carry on the parametric design on $\mathrm{it}^{[4]}$. Combined with the intent of designers for to establish the entity structure analysis, determine the sequence characteristics of the 
establishment of the. In order to avoid generating too much redundant code, make the driving parameter size is as small as possible, as far as possible, the procedures of establishing simplified characters. Open the macro recording ${ }^{[5]}$, creating entity in SolidWorks and uses the variable labeling parameter size, as shown in Fig.2 and in Fig.3. Macro recorded received basic codeentity established, according to the macro file objects and methods in their application in a reasonable organization, slightly modified, the specific parameters used variables instead of through the control of variables, this can realize the parameterized modeling straight shank ball end cutter blank and wheel, the operation results such asFig. 4 and Fig. 5.

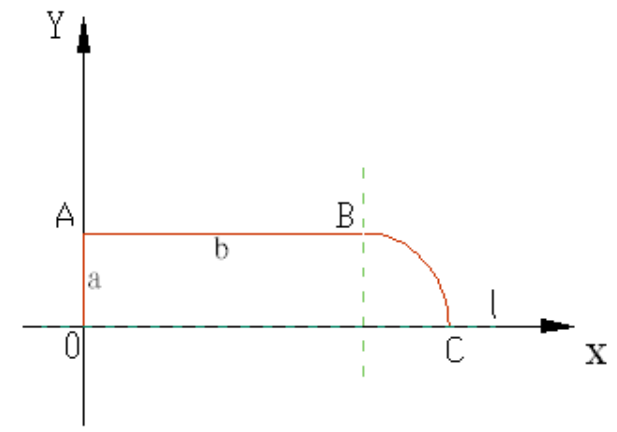

Fig. 2 Straight shank cutter grinding wheel blank

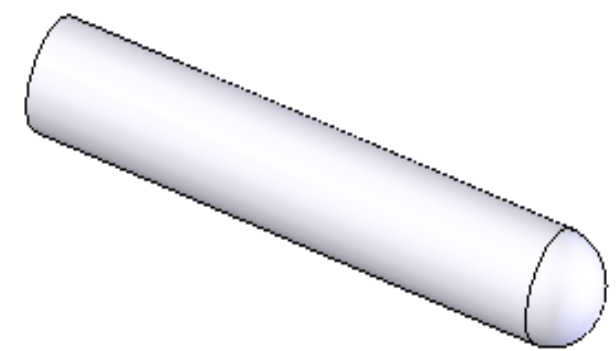

Fig. 4 Straight shank ball end cutter blank

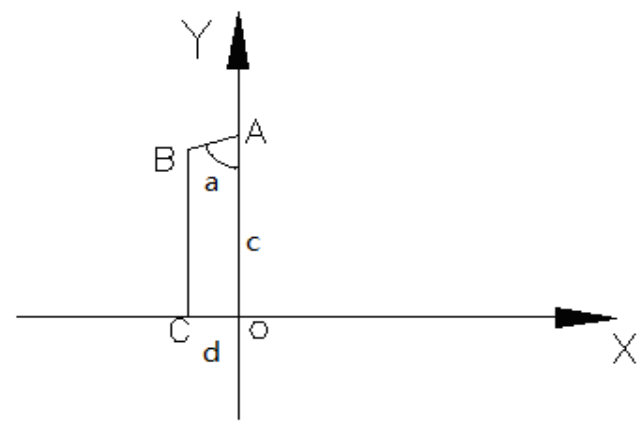

Fig 3 Sketch sketch

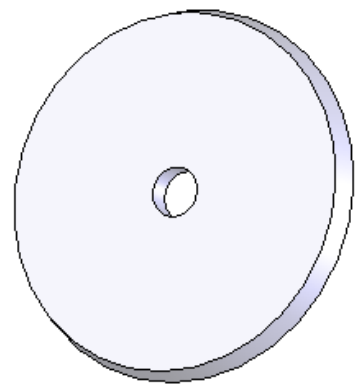

Fig. 5 Grinding wheel

\section{Straight shank ball end cutter grinding simulation}

To realize the simulation of rake face grinding of using solid modeling function of SolidWorks software. In accordance with the straight handle the ball end cutter locationpreparation formed right exercise program, cutter grinding wheel blank entity and entitycalled parametric modeling generated, using motion program control wheel deflectionand mobile, set difference operation through Boolean entity ${ }^{[6]}$, realizes grinding wheelsand mill blank, thus forming end rakeface and circumferential cutting edge rake face,as shown in Fig. 6.

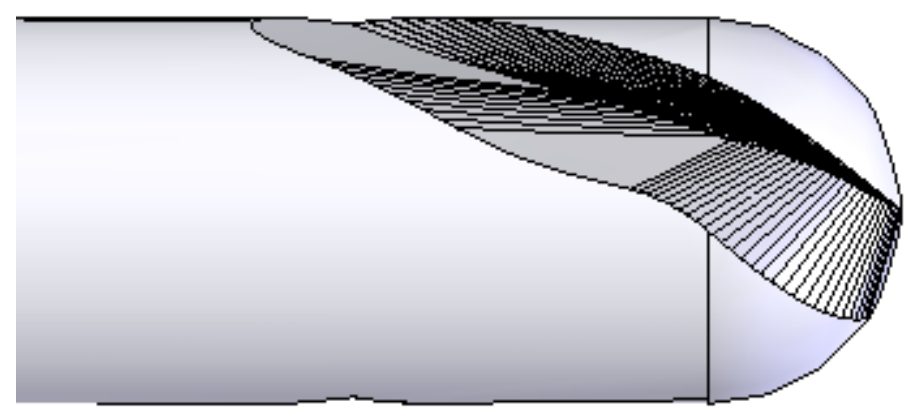

(a)

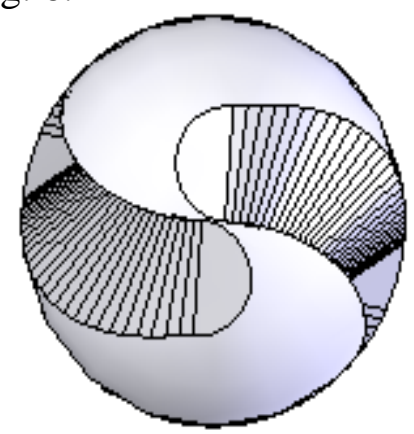

(b)

Fig. 6 the rake face grinding simulation results

\section{Analysis of simulation results}

Cutter end edge shape with $\mathrm{S}$ arc-shaped blade is better ${ }^{[7]}$, ensure stable cutter cut out the 
workpiece in the entry, and does not generate local larger wear, improve the tool endurance; Zhou edge rake face and end rakeface can realize smooth transition,ensure good machining quality, milling cutter the cutting performance and chip removal ability; there was a narrow edge near the edge part. Theblade is positive chamfering shape, can play a roll chip, chip removal effect, is beneficial to improving the penetration strength and cutting fluid cutting edge of themilling cutter. With a diameter of $10 \mathrm{~mm}$ straight shank ball end mill as an example,when the installation angle of the grinding wheel is $1=32$ degrees, $2=0$ degrees of sigma sigma, the relationship between edge width distribution and ball edge portion of the angle as shown in Table 1, shown in Fig. 8, we can see that the edge widthfrom the ball head ends to the circumference part of a "small big small" distribution,which is near the top and the circle is very small, is almost 0 larger, central.

Table 1 Edge width measurement results

\begin{tabular}{lll}
\hline $\begin{array}{l}\text { Serial } \\
\text { number }\end{array}$ & $\begin{array}{l}\text { The } \\
\text { ball blade angle } \\
\theta\end{array}$ & Edge width $(\mathrm{mm})$ \\
\hline 1 & $7.14^{\circ}$ & 0 \\
2 & $13.47^{\circ}$ & 0.006 \\
3 & $18.27^{\circ}$ & 0.035 \\
4 & $22.86^{\circ}$ & 0.072 \\
5 & $27.33^{\circ}$ & 0.115 \\
6 & $31.75^{\circ}$ & 0.159 \\
7 & $36.18^{\circ}$ & 0.200 \\
8 & $40.70^{\circ}$ & 0.235 \\
9 & $45.43^{\circ}$ & 0.261 \\
10 & $50.53^{\circ}$ & 0.272 \\
11 & $56.29^{\circ}$ & 0.260 \\
\hline
\end{tabular}

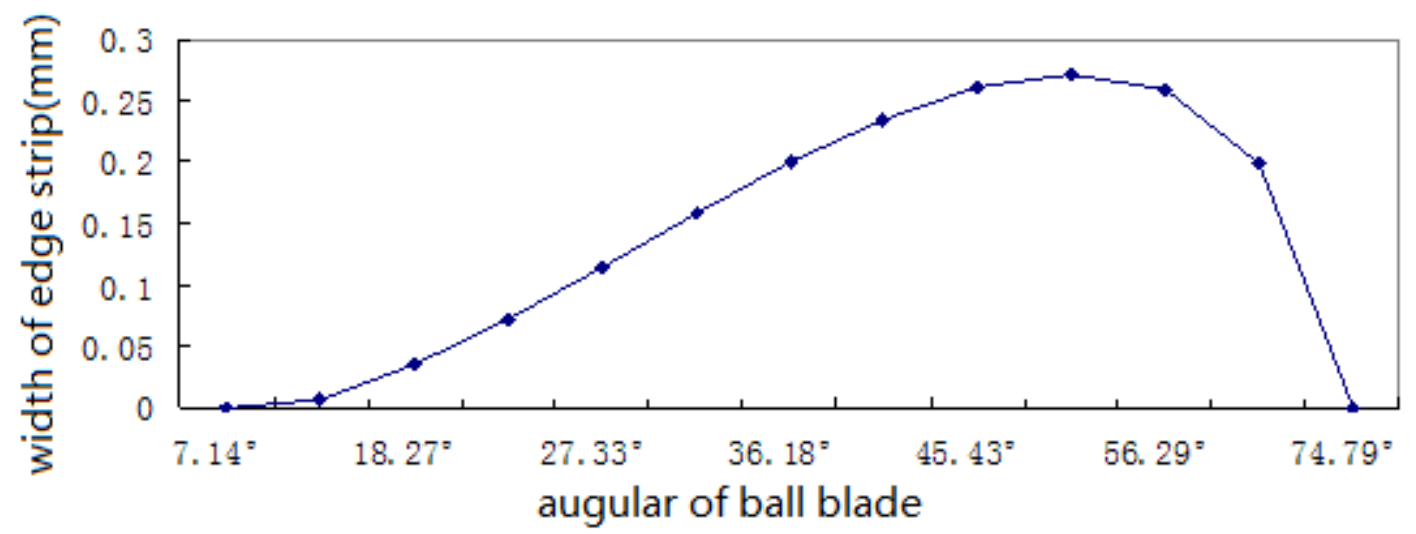

Fig. 8 angle - edge width distribution map

\section{Conclusion}

Machining simulation system is established in this paper to simulate the straight shankball end cutter rake face grinding process, verified the relationship between milling cutter grinding motion, to predict the cutting edge curve of actual processed, provides a theoretical basis for optimizing grinding parameters for later edge. Through the simulation found that the end edge has a good "S" shaped curve, smooth connection end edge and the circumferential cutting edge, on the end edge with a narrow blade.This system can simulate many kinds of cutting tool in cutting process is true,accurate and complex shape parts, can avoid the site several times to try cutting time and material brings on the waste, shorten the design cycle. 


\section{References}

[1] Zhao Xianfeng. Non dualresearch of worm and worm gear transmission [D]. Guizhou University master's thesis, 2007,6.

[2] He Lin, Li Shuai. The ball end cutter rake face grinding of the end edge simulation[J]. Mechanical design and manufacture, 2009 (2): 250 251.

[3] Numerical control programming and development of [DB/OL]. Baidu library, 2010,9.

[4] Jiang Hong, Wei Zheng, Wang Taowei. Two instances of Solid Works secondary development analysis [M]. Mechanical Industry Press, 2004.

[5] Li Shuai. Two development and the parameters of the SolidWorks design[J]. Journal of Zaozhuang University, 2010 (2): 79 82.

[6] SolidWorks Corporation.SolidWorks 2005 API help [Z].2005.

[7] He Biao. Model of ball end mill grinding master's degree thesis [D]. study on processing of Guizhou University, 2005,6. 